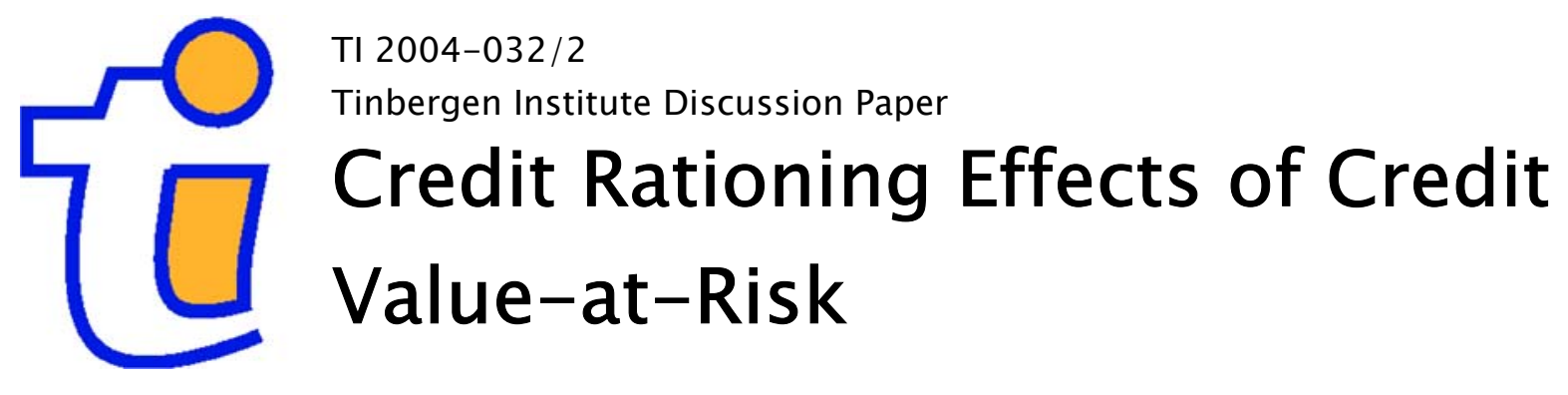

Jan Frederik Slijkerman*

David J.C. Smant

Casper G. de Vries*

Faculty of Economics, Erasmus Universiteit Rotterdam.

* Tinbergen Institute. 


\section{Tinbergen Institute}

The Tinbergen Institute is the institute for economic research of the Erasmus Universiteit Rotterdam, Universiteit van Amsterdam, and Vrije Universiteit Amsterdam.

Tinbergen Institute Amsterdam

Roetersstraat 31

1018 WB Amsterdam

The Netherlands

Tel.: $\quad+31(0) 205513500$

Fax: $\quad+31(0) 205513555$

Tinbergen Institute Rotterdam

Burg. Oudlaan 50

3062 PA Rotterdam

The Netherlands

Tel.: $\quad+31(0) 104088900$

Fax: $\quad+31(0) 104089031$

Please send questions and/or remarks of nonscientific nature to driessen@tinbergen.nl.

Most TI discussion papers can be downloaded at http://www.tinbergen.nl. 


\title{
Credit Rationing Effects of Credit Value-at-Risk
}

\author{
Jan Frederik Slijkerman David J.C. Smant \\ Casper G. de Vries \\ Erasmus University Rotterdam and Tinbergen Institute
}

March 12, 2004

\begin{abstract}
Banks provide risky loans to firms which have superior information regarding the quality of their projects. Due to asymmetric information the banks face the risk of adverse selection. Credit Value-at-Risk (CVaR) regulation counters the problem of low quality, i.e. high risk, loans and therefore reduces the risk of the bank loan portfolio. However, CVaR regulation distorts the operation of credit markets. We show that a binding CVaR constraint introduces credit rationing and lowers social welfare. CVaR regulation also affects the operation of monetary policy.
\end{abstract}

\section{Introduction}

The Value-at-Risk (VaR) approach to financial risk management is increasingly being used by regulators to set capital requirements for banks and other financial intermediaries. The current regulation for banks according to the 1988 Basel Accord is outdated. The 1988 Accord insufficiently differentiates between different credit risks and it does not recognize risk-mitigation techniques and diversification effects. The internal model based VaR approach is intended to overcome these drawbacks for market risk. The new Basel 2 framework will allow the use of those VaR techniques to evaluate credit risk. This should improve regulatory incentives by connecting the regulatory capital more closely to the actual credit risk as estimated by banks. However, 
the general equilibrium effects of this new framework are not yet completely understood. We investigate the ramifications of CVaR regulation for the operation of credit and deposit markets.

The Accord allows for two main approaches to evaluate credit risk inherent in individual loans. Banks may use a standardized approach to risk assessment, employing the ratings provided by external credit rating agencies, or alternatively, banks with sufficiently developed risk assessment systems may use an internal-ratings-based method to estimate the credit risk of their portfolios. Regardless the system being used, whenever the regulatory capital constraint becomes binding, this imposes an upper bound on the risk of the portfolio.

The consequences of the introduction of simple and risk-weighted capital adequacy requirements have been studied intensively. A theoretical overview of the need for banking supervision and the consequences for incentives can be found in Freixas and Rochet (1997) and Dewatripont and Tirole (1994), who study the microeconomic foundations of the banking industry. The Basel Committee on Banking Supervision (1999) provides a good overview of the empirical impact of the 1988 Accord. In this paper we show that a Credit risk model based Value-at-Risk (CVaR) constraint, when binding, induces credit rationing by banks.

From the literature we know that imperfect information on loan applicants can cause credit rationing, see Stiglitz and Weiss (1981) and Williamson (1986). However, the influence of bank regulation is absent from these models. Thakor (1996) models bank lending in the case of adverse selection and bank capital requirements. He does not, however, model VaR regulation. To the best of our knowledge the effect that CVaR regulation induces credit rationing is novel to the literature.

Understanding the distortionary effects on the credit market of Value-atRisk based regulation is important, but the bank loan market is also relevant for monetary policy. Mishkin (1996) provides an overview of the broad literature on the transmission channels of monetary policy. Dissatisfaction with conventional views of how interest rates explain the effects of monetary policy has recently led to a revival of the credit channel of monetary policy.

The credit channel approach to monetary policy consists of both a general credit channel and a lending channel. According to the general balance sheet channel theory, the effects of monetary policy on interest rates are amplified by endogenous changes in the external finance premium, which is the difference in cost between funds raised externally and funds generated 
internally (Bernanke and Gertler (1995), see also Hubbard (2000)). The size of this premium reflects imperfections in the credit markets. According to the bank lending channel of monetary policy bank credit is special for firms. The information problem in the supply of credit from banks to firms generates frictions which make it difficult for banks to increase the supply of credit when demand rises. We model this friction in bank loan supply explicitly. Stein (1998) shows that asymmetric information between depositors and banks generates frictions in the lending channel. We model another aspect of the lending channel by modelling asymmetric information between banks and borrowing firms, which results in adverse selection.

To demonstrate that CVaR regulation may induce credit rationing, we adopt a standard model from the literature. The model was first developed by Jaffee and Russel (1976) and Mankiw (1986). Freixas and Rochet (1997) contains a concise description of the model. The contribution of the paper is not in the development of a new model of the credit market, though we extend the model by endogenizing the supply of deposits ${ }^{1}$. This closure of the model helps to gauge the equilibrium effects of the Basle regulatory requirements.

The outline of the paper is as follows. The basic model of the bank loan market is presented in section 2. We first model the supply of bank loans in case of adverse selection and in the absence of regulation. In section 3 we introduce the Value-at-Risk constraint of credit risk regulation and show that CVaR regulation induces credit rationing. Section 4 concludes our paper.

\section{The bank loan market}

Our model is a one period loan market in the spirit of Mankiw (1986). We assume that each firm can invest in a project that has a size of one unit. All firms are identical except for their probability of success on the project. Each project has two possible gross returns. These are $X / \theta$ with probability $\theta$ and zero with probability $(1-\theta)$. Hence, the expected gross return for firms is $X$, and the variance is $\frac{1-\theta}{\theta} X^{2}$.

The risk parameter $\theta$ of individual firms is assumed to be distributed on the interval $[\alpha, \beta]$ (with $0 \leq \alpha<\beta$ ). Firms know their own risk parameter $\theta$, but do not know the actual outcome of their project. Suppliers of external finance, i.e. banks, only know the sample distribution of $\theta$ for all firms. Thus

\footnotetext{
${ }^{1}$ With endogenous supply of deposits credit markets do not completely collapse, whereas they otherwise might, c.f. Mankiw (1986) and Freixas and Rochet (1997).
} 
there is an asymmetry in information between what banks know and the knowledge of the individual entrepreneurs. Since banks cannot discriminate, bank loans can be obtained at the (gross) interest rate $R(R \geq 1)$.

\subsection{The demand for bank loans}

The firms net return depends on the loan repayment at the going gross rate $R$. Since the legal system offers firms limited liability, we assume that risk neutral banks offer standard debt contracts with limited liability. Adding up, the firm per unit (loan) profit function $P^{F}$ becomes

$$
P^{F}= \begin{cases}\frac{X}{\theta}-R & \text { with probability } \theta \\ 0 & \text { with probability } 1-\theta\end{cases}
$$

The expected profit for the firm is

$$
E\left[P^{F}\right]=\theta\left(\frac{X}{\theta}-R\right)=X-\theta R
$$

The variance is $(\alpha>0)$

$$
\operatorname{Var}\left[P^{F}\right]=\left(\frac{1}{\theta}-1\right)(X-\theta R)^{2}
$$

A risk neutral firm only invests if expected profit $E\left[P^{F}\right] \geq 0$. The participation constraint for firms is therefore satisfied when $\theta \leq \frac{X}{R}$. Note that the expected returns are an increasing function of risk, consistent with basic finance theory. We have the following proposition concerning demand

Proposition 1 The total demand for bank loans is decreasing in $R$ if $\beta R$ is larger than $X$ and the demand for loans is insensitive to $R$ if $\beta R \leq X$.

Proof. By the assumption that $\theta$ has support $[\alpha, \beta]$, all projects will be undertaken when $\beta R \leq X$ since at $\beta R=X$ the participation constraint is satisfied for all firms and a reduction of $R$ will not increase the number of firms demanding credit. If $\beta R>X$, only firms with $\theta \leq \frac{X}{R}<\beta$ are active. Firms on the interval $\left[\alpha, \frac{X}{R}\right]$ apply for bank loans and the proportion of firms investing is a declining function of $R$.

Note that $\frac{\frac{X}{R}-\alpha}{\beta-\alpha}$ represents the proportion of viable investment projects. To obtain total demand for credit we will scale this proportion by a factor 
$c$. The scaling factor $c$ indicates the maximum potential market size. The demand for loans when $\beta R>X$ becomes $D^{d}=c \frac{\frac{X}{R}-\alpha}{\beta-\alpha}$, otherwise $D^{d}=c$.

In the following we derive the expected return for banks on their portfolio. Let the average probability of success be denoted as $\pi=E[\theta]$. When $\beta R \leq X$ all firms invest, the average probability of success is

$$
\pi=\int_{\alpha}^{\beta} \theta f(\theta) d \theta
$$

When $\beta R>X$, the average probability of succes equals the conditional expected value of $\theta$ for all firms that want to invest

$$
\pi(R)=E\left(\theta \mid \frac{X}{R} \geq \theta\right)=\frac{1}{F\left(\frac{X}{R}\right)} \int_{\alpha}^{\frac{X}{R}} \theta f(\theta) d \theta .
$$

Note that at any given loan rate the firms that choose to invest and turn out to be successful are always able to repay the bank loan in full, since for these firms $R \leq \frac{X}{\theta}$.

\subsection{The supply of bank loans}

Banks provide loans to firms at an interest rate $R$. Banks fund these loans in the deposit market, facing a cost of funding $I$, the equilibrium interest rate on the deposit market. Moreover, banks have to pay an actuarially fair insurance premium to take into account the costs of failing loans. This is to prevent banks from moral hazard which arises out off the limited liability constraint. Banks have to pay the actuarial fair insurance premium $(1-\pi(R)) I$. Because a firms' individual $(X, \theta)$ combination is private information of the borrower, $R$ cannot be conditioned on this information. All funded projects are charged the same interest rate $R$. The expected per unit profit function for the bank is thus

$$
\begin{aligned}
E\left[P^{B}\right] & =\pi(R)(R-I)-(1-\pi(R)) I \\
& =\pi(R) R-I .
\end{aligned}
$$

This profit function consists in two parts. The first part, $\pi R$, denotes the expected gross return of all loans to firms that are successful. The second 
part, $I$, defines the funding costs of the bank loans. In a perfectly competitive market, bank profits are zero ${ }^{2}$. In equilibrium the required expected probability of repayment from the pool of borrowers would be

$$
\pi=\frac{I}{R}
$$

\subsection{The deposit market}

When banks want to increase their loan volume they have to attract more funding for these loans. The nonbank public will increase deposit holdings if the deposit interest rate $I$ is higher. We model the deposit market rate $I$ endogenously, cf. Mankiw (1986), who takes deposit supply exogeneous. The deposit rate is a positive function of the quantity of deposits that needs to be supplied, $D^{s}$. For simplicity we assume a linear supply schedule. The inverse supply curve of bank deposits by the nonbank public therefore is

$$
I=a+b D^{s}, \quad a \leq 1, b>0
$$

\subsection{Equilibrium}

In this subsection we characterize the equilibrium in the loan market in absence of regulation. We know the demand and the supply of loans by banks, depending on the deposit market interest rate $I$. Assume that $\theta$ follows a uniform distribution, cf. Mankiw (1986). Deposit market equilibrium requires $D^{s}=D^{d}$ where $D^{d}=c$ if $\beta R \leq X$, and $D^{d}=c \frac{\frac{X}{R}-\alpha}{\beta-\alpha}$ if $\beta R>X$.

Although there is adverse selection in the model, we will see that this does not result in a complete collapse of the loan market, as is the case in the model of Mankiw (1986). Though as in all markets, when prices change quantities adjust, changes in $R$ do affect the amount of credit.

Proposition 2 There exists a unique equilibrium in the loan market if the project risk parameter $\theta$ follows a uniform distribution, $F(\theta)=\frac{\theta-\alpha}{\beta-\alpha}$.

Proof. From proposition 1 we have that either all firms invest or only part of the firms invest. If $\beta R \leq X$ all firms will invest. The equilibrium deposit rate and loan rate are determined by equations (3) and (4). We know $D^{s}=$

\footnotetext{
${ }^{2}$ The same modelling strategy is used in Mankiw (1986).
} 
$D^{d}=c$ and $\pi=E[\theta]=\frac{(\alpha+\beta)}{2}$, the unconditional expectation of $\theta$. Solving (3) and (4) for the equilibrium loan rate gives $R=\frac{a+b c}{(\alpha+\beta) / 2} \leq X / \beta$. If $\beta R>X$ only part of the firms invest and $D^{d}=c \frac{\frac{X}{R}-\alpha}{\beta-\alpha}$. We know the conditional expectation of $\theta$ from equation (2). Hence $\pi(R)=\frac{\beta-\alpha}{\frac{X}{R}-\alpha} \int_{\alpha}^{\frac{X}{R}} \frac{\theta}{\beta-\alpha} d \theta=\frac{1}{2} \alpha+\frac{1}{2} \frac{X}{R}$. Moreover, from the deposit market equilibrium $D^{s}=D^{d}$, we have $I=a+$ $b c \frac{\frac{X}{R}-\alpha}{\beta-\alpha}$. Since $\pi(R)$ and $I(R)$ are functions of $R$, we find the equilibrium interest rate $R$ if we solve equation (3). Rewrite (3) to define $H(R)=$ $\pi(R) R-I(R)$. In equilibrium $H(R)=0$. Multiply $H(R)$ by $R$ to obtain a second order polynomial in $R$. The equilibrium condition reads

$$
R H(R)=\frac{1}{2} \alpha R^{2}+\left(\frac{1}{2} X-a+\frac{\alpha b c}{\beta-\alpha}\right) R-\frac{X b c}{\beta-\alpha}=0 .
$$

This function is convex and is negative at $R=0$. Therefore there exist a positive and a negative root. Thus there exists a unique solution $R>0$.

The fact that there always exists an equilibrium in this model is interesting because it is contrary to the results of Mankiw (1986). Mankiw finds that the credit market may collapse when $R$ becomes too high. The reason for the collapse is that the deposit rate $I$ in Mankiw's model is held fixed. Because we model the deposit market endogenously, the market never completely collapses.

\subsection{A graphical exposition}

We depict loan supply and demand graphically. Assume $\theta \sim U[0,1]$, i.e. $\alpha=0, \beta=1$. Figure 1 displays the market equilibrium in the $(R, \pi(R))$ plane using the shape of the iso-profit curve (equation (3)) and the shape of the expected repayment curve (equation (2)). As mentioned before, all firms want to participate in the loan market if $R \leq X$ and this results in $\pi=\frac{1}{2}$. This fact is represented by a straight line segment in the $R, \pi(R)$ plane until the cost of borrowing, $R$, becomes too high at $R=X$, and the firms with high $\theta$ decide no longer to invest. This is the point where the adverse selection kicks in. Higher bank loan rates, $R>I$, are associated with lower $\pi$. The supply of bank loans is decreasing in $R$. The equilibrium in case of adverse selection is

$$
(R, \pi(R))=\left(\frac{b c X}{X / 2-a}, \frac{1}{b c}(X / 4-a / 2)\right) .
$$




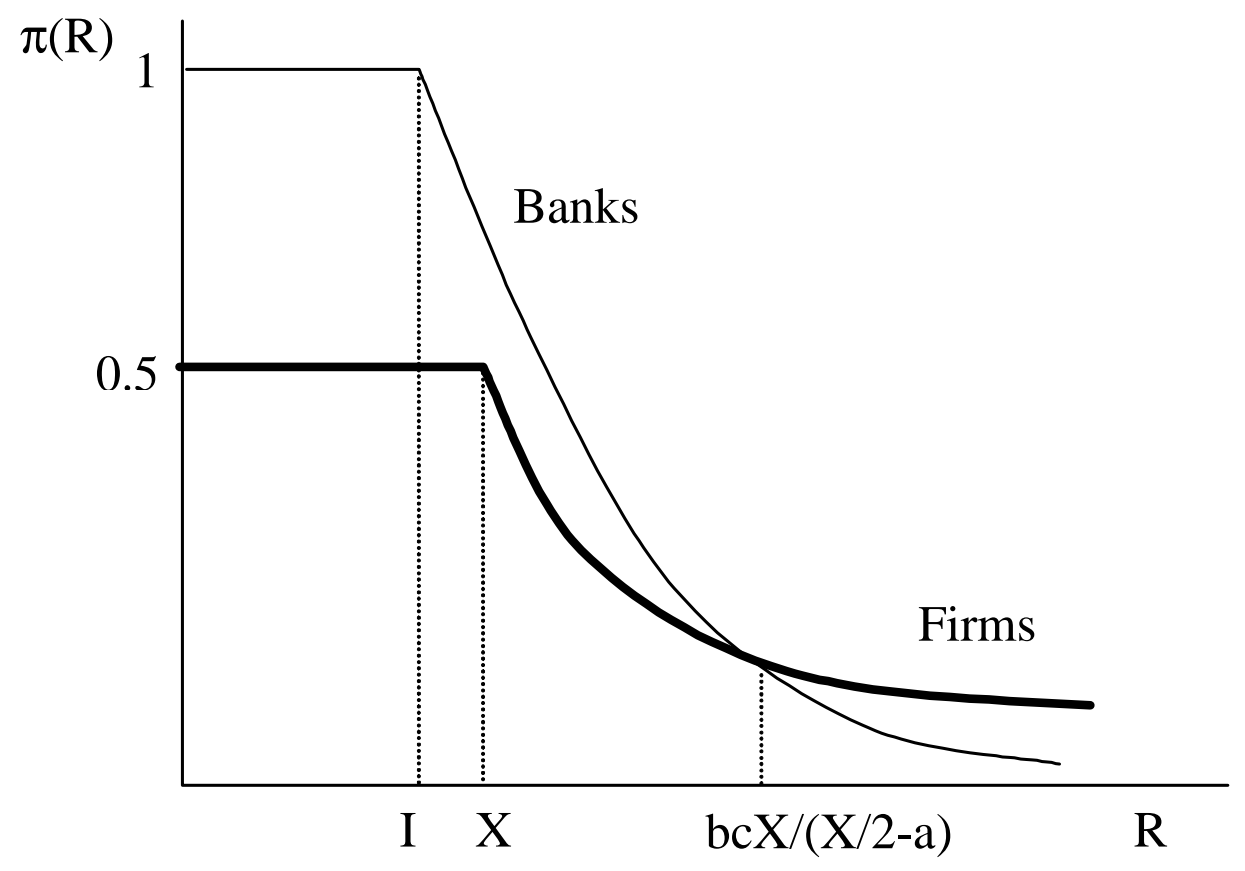

Figure 1: Bank loan market equilibrium

Now that we have studied equilibrium in case of absence of regulation, we will investigate the equilibrium effects of regulation.

\section{Credit risk regulation}

The motive for the minimum regulatory risk constraint for the bank loan portfolio is to counter adverse selection and to improve social welfare. We first demonstrate this motive for Basel II type regulation. Subsequently we show that this regulation implies credit rationing.

\subsection{Social Welfare}

The intuition behind CVaR regulation is that it counters adverse selection and too high interest rates. To validate regulatory intervention, to bring 
down interest rates, we investigate if there is scope for improving the quality of investments. Social welfare is the sum of welfare for firms, welfare for banks and welfare for depositors. Since we assume perfect competition in the banking industry, welfare for banks is zero. Welfare for firms is determined by the sum of the expected profits of viable projects and equals the expected returns multiplied by total demand. The expected profits are the difference between the expected returns and the expected costs. For the time being, we only investigate the possibility to raise the average quality of the projects. The deposit rate will be held constant and therefore the welfare for depositors as in Mankiw (1986). Later, we will look at the welfare implications of the Credit Value at Risk constraint, when the deposit market is modelled endogeneously.

Proposition 3 At equilibrium, social welfare would be enhanced by a ceteris paribus reduction in $R$.

Proof. First consider that equilibrium is determined by the interest rate $R$, under the constraint $\pi(R) R=I$. We keep $I$ constant so as to guarantee there is no welfare loss for deposit holders. At equilibrium the gross expected revenue of the undertaken project is $X$. The expected funding costs are $\pi(R) R$. We know $\pi(R) R=I$ by the competition in the banking sector. Expected social welfare at equilibrium thus equals $X-\pi(R) R=X-I$. To show that the expected social welfare is higher in case of a reduction in $R$ we have to determine whether for the population of marginal borrowers the average of excess return $(X-I)$ is positive. We know that for the marginal borrower $X=\theta R$ and therefore we investigate whether $\theta R-I$ is positive. From the zero profit condition for banks we know that $\pi(R) R-I=0$. Since for the marginal borrower $\theta>\pi(R)$ we get that the average of excess returns $(X-I)$ is positive.

Therefore CVaR regulation has the potential to improve social welfare if supply of deposits is perfectly elastic at the given deposit rate $I$. The intuition is that banks attract better quality loans by lowering $R$. This is the aim of the new Basel accord, which hopes to improve the quality of the loan portfolio by CVaR regulation. Supply of deposits is not perfectly elastic however, so that in equilibrium $\mathrm{CVaR}$ regulation results in a lower deposit market interest rate. From the previous proposition we know that an improvement in welfare might be possible. In the following we will first look at the equilibrium effects of the Basel type of regulation, thereafter we will study the consequences for social welfare. 


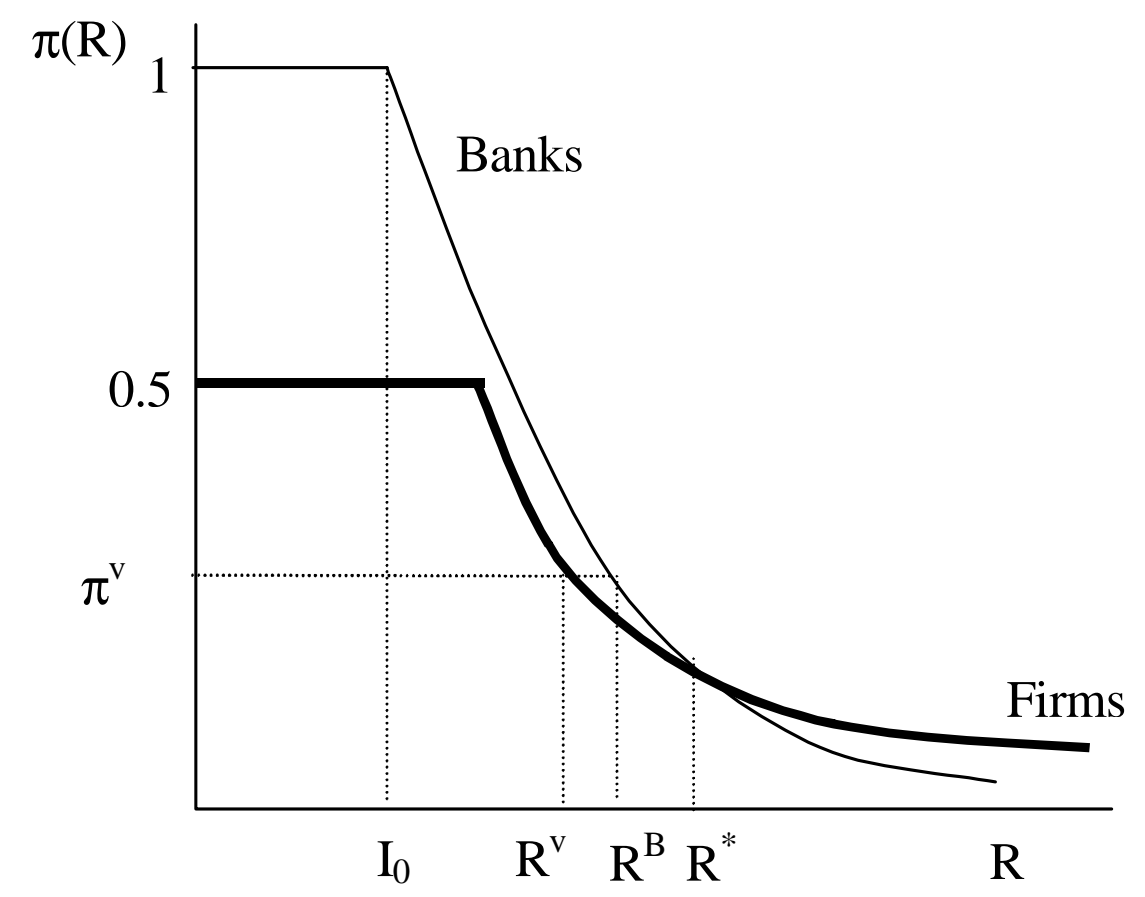

Figure 2: Bank loan market and credit risk constraint

\subsection{The credit risk constraint}

Consider a banking supervisor and banking regulation under the planned Basel II accord. We assume that the supervisor has no better information than the bank. For this reason the supervisor imposes a risk limit using the average success rate of loans $\pi$ in order to improve the quality of the loan portfolio. Note that the quality of the loan portfolio is strictly increasing in $\pi(R)$ and hence decreasing in $R$. Suppose therefore that credit risk regulation imposes a lower limit on the average probability of success on repayment $\pi(R)$, say $(1-\pi(R)) \leq \delta$. We call $\delta$ the CVaR constraint on the loan book.

Figure 2 displays the credit risk constraint effective at the bank loan portfolio risk level $\pi^{v}$, where $\pi^{v}=1-\delta$. Again, assume $\theta \sim U[0,1]$, i.e. $\alpha=0$, $\beta=1$. The iso-profit curve of the firms requires that the loan rate is no higher than $R^{v}$. From equations (3) and (4) and the equilibrium result (5), one sees that when the risk restriction binds, $R^{v}<I_{0} \pi^{-1}=I_{0} b c(X / 4-a / 2)^{-1}$. Here 
$I_{0}$ refers to the deposit rate which prevails in the unconstrained equilibrium $\left(R^{*}, \pi\left(R^{*}\right)\right)$ or $\left(b c X(X / 2-a)^{-1},(X / 4-a / 2)(b c)^{-1}\right)$. At the lower interest rate $R^{v}$ the quality (success rate) of the pool of loan contracts is higher, since more firms with relatively high quality projects apply for a loan, compared to the unconstrained equilibrium. So both the average quality as well as the number of loans demanded increases. At $\pi^{v}$ and a given deposit rate $I_{0}$ banks require a loan rate of no less than $R^{B}$. In this situation loan demand and supply do not meet. What does it take for banks to be willing to offer $\left(R^{v}, \pi^{v}\right)$ ? This requires a shift in the bank iso-profit curve to the left. For the moment we will give the intuition behind this statement. Note that the bank iso-profit curve implicitly defines the bank supply curve for loans. From (3) it follows that the only shift parameter of this curve is the deposit rate $I$. By lowering $I$, the loan supply curve shifts to the left until it cuts the demand curve at $\left(R^{v}, \pi^{v}\right)$. Assuming that the supply curve for deposits is an upward sloping function of the deposit rate, banks can reduce the deposit market rate by taking in fewer deposits. The implication of a lower deposit demand is a reduction in the supply of loans. Thus while at $\left(R^{v}, \pi^{v}\right)$ the demand for loans increases vis a vis the free market solution, the supply is reduced. Loan market equilibrium can then be achieved only if banks ration the supply of bank loans at the given quality level $\pi^{v}$. The quality of the loan portfolio must at least be $\pi^{v}$. This condition can be met in expectation since banks necessarily select the loan applicants randomly. Thus the equilibrium under a binding $\mathrm{CVaR}$ constraint involves random credit rationing.

We will now prove this formally. When the CVaR constraint is binding we have $\pi^{v} R=I$. Solving for $R$ using the firms investment demand function, we find

$$
R^{v}=\frac{X}{\pi^{v}}
$$

The Value at Risk constraint is binding if $R^{*}>R^{v}$, where $R^{*}$ denotes the unconstrained equilibrium loan rate.

Deposit market equilibrium requires $D^{s}=D^{d}$ where $D^{d}=c$ if $R \leq X$, and $D^{d}=c \frac{X \frac{X}{R}-\alpha}{\beta-\alpha}$ if $\beta R>X$. The zero profit condition for banks implies $\pi R=I$ and the supply of deposits is determined by $D^{s}=\frac{I-a}{b}$. We have the following result

Proposition 4 Equilibrium in a credit market with binding $C V a R$ regulation involves random credit rationing if $\beta R^{*}>X$ and $\theta \sim U[\alpha, \beta]$. 


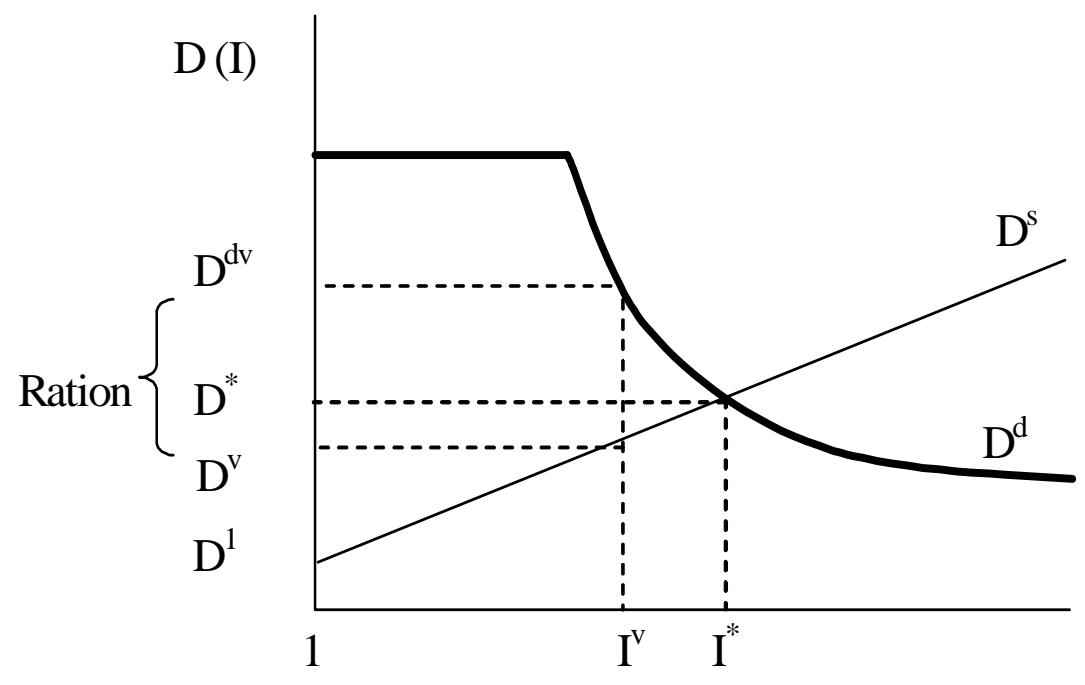

Figure 3: Deposit market

Proof. If $\beta R^{*}>X$ we know equilibrium in the deposit market implies $D^{s}=D^{d}$. Introducing the portfolio quality constraint decreases $R$ from $R^{*}$ to $R^{v}$. The demand for deposits $D^{d}$ rises since $D^{d}=c \frac{\frac{X}{R}-\alpha}{\beta-\alpha}$ and $\frac{d D^{d}}{d R}<0$. Because of the lower $R$, the funding cost for banks, $I$, has to decrease, since $I=\pi(R) R=\frac{1}{2} \alpha R+\frac{1}{2} X$ and $\frac{d I}{d R}>0$. However, a lower deposit rate will lower deposit supply, since $D^{s}=\frac{I-a}{b}$ and $\frac{d D^{s}}{d I}>0$. Hence, $D^{s}<D^{d}$ if $R$ decreases from $R^{*}$ to $R^{v}$ so that the supply of deposits will not meet demand.

In figure 3 we show the effect of VaR regulation on total deposit demand. Rationing keeps the loan quality at $1-\delta$. The excess demand for deposits, given $I^{v}$, is the difference between $D^{d v}$ and $D^{v}$. Banks have to ration firms and only a fraction $\frac{D^{v}}{D^{d v}}$ of the firms obtains loans.

Now that we have found the equilibrium in the credit market in case of $\mathrm{CVaR}$ regulation, we like to investigate whether this improves social welfare or not for the case when deposit supply is not perfectly elastic. Regulation improves the quality of the loan portfolio, but there are two adverse effects lowering welfare. The most important effect is credit rationing, lowering the number of firms obtaining financing. The second effect is the lower deposit market interest rate, lowering the welfare surplus for depositors $\left(W^{d}\right)$. In the $(I, D)$ plane the welfare for depositors is equal to the surface of the triangle established by the points $\left(I^{*}, D^{*}\right),\left(0, D^{*}\right)$ and $\left(1, D^{1}\right)$ (where $I^{*}$ and 
$D^{*}$ denote the equilibrium deposit rate en equilibrium deposit supply). We show that total welfare will decrease.

Proposition 5 CVaR regulation lowers social welfare.

Proof. We have to evalate two cases. Welfare by firms $\left(W^{f}\right)$ can be increasing in the deposit rate (the first case, $\frac{d W^{f}}{d I}>0$ ) and welfare by firms can be decreasing in the deposit rate. If welfare by firms is decreasing in the deposit rate (case 2) we have to evaluate whether the welfare gain by firms is larger than the welfare loss for depositors. Total welfare by firms is equal to the expected welfare by individual firms, $X-I$ (as is shown in the proof of proposition (3)) multiplied by total demand, $W^{f}=D(X-I)$ where $D=\frac{I-a}{b}$. The first case $\left(\frac{d W^{f}}{d I}>0\right)$ holds if $X+a-2 I>0$ and in this case CVaR regulation unambiguously lowers social welfare. In the second case $\frac{d W^{f}}{d I}<0$. Let $D^{*}\left(X-I^{*}\right)$ denote the quantity of loans made in absence of regulation multiplied by the average firm welfare in absence of regulation. Let $D^{v}\left(X-I^{v}\right)$ denote the quantity of loans made in case of regulation multiplied by the average firm welfare in case of regulation. The increase in welfare by firms $\left(d W^{f}\right)$ is the difference between $D^{v}\left(X-I^{v}\right)$ and $D^{*}\left(X-I^{*}\right)$. The welfare loss for depositors is equal to $\left(I^{*}-I^{v}\right) D^{v}+\frac{1}{2}\left(I^{*}-I^{v}\right)\left(D^{*}-D^{v}\right)$. The increase in welfare is positive if $d W^{f}>d W^{d}$ or

$$
D^{v}\left(X-I^{v}\right)-D^{*}\left(X-I^{*}\right)>\left(I^{*}-I^{v}\right) D^{v}+\frac{1}{2}\left(I^{*}-I^{v}\right)\left(D^{*}-D^{v}\right)
$$

which is equivalent to $X<\frac{I^{*}+I^{v}}{2}$. This is not the case since $X \geq I^{*}>I^{v}$.

It is interesting to note that regulation $Q$ in the United States had similar consequences as the risk constraint $\delta$. Under regulation $\mathrm{Q}$ in the United States and similar arrangements elsewhere, the regulator imposed an upper limit on the deposit rate. This ceiling on the deposit rate was imposed until april 1986. The main justification for a maximum deposit rate was that it would lower the funding costs for banks. However, it induces credit rationing, as is stated in the following

Corollary 6 Regulation $Q$ has similar effects as the risk constraint $\delta$

Proof. Regulation Q limits $I$ to $I^{Q}<I$. When this constraint is binding, it is straigtforward to show that the supply of loans is lower than the demand for loans (the proof is similar to the proof of proposition 4) and therefore there will be credit rationing. 
By limiting the deposit rate $I$ to a maximum, banks face an excess demand for loans, as is the case with the risk constraint $\delta$. To achieve equilibrium the deposit rate should be higher. In this case the constraint is on the deposit interest rate rather than on the loan quality, but the effects are identical.

\subsection{Effect on monetary policy}

We have seen in the previous section that a binding $\mathrm{CVaR}$ restriction requires the deposit rate to fall and therefore induces a fall in the volume of bank deposits. In macroeconomic models the fall in bank deposits equals a reduction in the money supply, and in the familiar ISLM model this can be visualized as a leftward shift of the LM curve. Moreover, credit rationing induced by the CVaR restriction reduces firms' investment spending and shifts the IS curve to the left as well. Clearly, without a monetary policy response, the combined shifts of the LM and IS curves due to the regulatory CVaR shock could cause a significant reduction in macroeconomic activity.

Empirical research on the effects of bank capital regulation has focused on the introduction of the minimum capital requirements of the 1988 Basle Accord. We are not aware of empirical evidence on the relationship between bank capital regulation and credit rationing of individual firms. In fact, there are very few studies offering any direct evidence on credit rationing. With regard to the reduction in bank deposits, preliminary results in a study by Smith (2002) suggest that the introduction of Basle I lowered the growth rate of the money supply, consistent with our model. Most studies on the introduction of the 1988 Basle Accord have examined its effects on the overall volume of bank lending, and some studies investigated whether banks shifted the composition of their balance sheets towards or away from risky asset types. The evidence for G-10 countries on the response of banks to the enforcement of the 1988 capital adequacy requirements are surveyed in Basel Committee on Banking Supervision (1999). The paper's main finding is that "there is some evidence that bank capital pressures during cyclical downturns in the US and Japan may have limited bank lending in those periods and contributed to the economic weakness in some macroeconomic sectors". However, the report also states that the effects "may well have reflected both regulatory and market pressures". Sharpe (1995), following his survey of the literature, argues that the evidence in favor of a capital crunch in the United States during 1989-1992 is inconclusive; the only exception being the evidence for banking in New England where the support for a capital crunch is 
reasonably firm. All in all, it would take more empirical research to pinpoint the effects of Basle I on credit, but at least there is some empirical evidence which supports our theory.

\section{Conclusion}

In the first part of the paper we have extended a microeconomic model of credit provisioning in case of asymmetric information. By making the cost of funds for banks dependent on the deposit market interest rate, we show that there always exists an equilibrium in the market for bank loans. The adverse selection effect which lowers the loan volume when the loan rate rises, is countered by lower costs for banks, because of a lower deposit rate. In the second part we discuss current proposals for a new Basle capital adequacy accord which sponsor the idea that banks should be allowed to use internal credit risk models to compute the required capital adequacy on bank loans, in contrast to the existing but outdated Basle I standards. We have shown that a credit risk model based Value-at-Risk constraint when binding, distorts the operation of credit markets as it involves credit rationing. It was shown that this type of regulation lowers social welfare.

\section{References}

[1] Basle Committee on Banking Supervision, 1999, Capital requirements and bank behavior: The impact of the Basle Accord, Working Papers no.1, BIS, Basle

[2] Bernanke, B.S. and M. Gertler, 1995, Inside the black box: the credit channel of monetary policy transmission, Journal of Economic Perspectives, 9: $27-48$

[3] Dewatripont, M. and J. Tirole, 1994, The Prudential Regulation of Banks. MIT Press

[4] Freixas, X. and J.C. Rochet, 1997, Microeconomics of Banking, MIT Press 
[5] Hubbard, R.G., 2000, Capital-market imperfections, investment, and the monetary transmission mechanism, paper prepared for presentation at Bundesbank, Frankfurt, Germany, May 2000. (www1.gsb.columbia.edu/faculty/ghubbard/Papers/capital2_bundesbank_00.pdf)

[6] Jaffee, D.and T. Russell, 1976, Imperfect information, uncertainty and credit rationing, Quarterly Journal of Economics 90: 651-66.

[7] Mankiw, N.G., 1986, The allocation of credit and financial collapse, Quarterly Journal of Economics 103: 101-130

[8] Mishkin, F.S., 1996, The channels of monetary transmission: Lessons for monetary policy. NBER working paper no.5464

[9] Sharpe, S.A., 1995, Bank capitalization, regulation, and the credit crunch: A critical review of the research findings, Board of Governors of the Federal Reserve System Finance and Economics Discussion Series no. $95-20$

[10] Smith, D., 2002, Quarterly macroeconomic model of the UK and World Economies (Working Draft), $11^{\text {th }}$ edition, Williams de Broë, London: $22-23$

[11] Stein J.C., 1998, An adverse-selection model of bank asset and liability management with implications for the transmission of monetary policy, RAND Journal of Economics 29: 466-486

[12] Stiglitz, J.and A. Weiss, 1981, Credit rationing in markets with imperfect information, American Economic Review, 71: 393-410

[13] Thakor A.V., 1996, Capital requirements, monetary policy, and aggregate bank lending: theory and empirical evidence, Journal of Finance 51: $279-324$

[14] Williamson, S.D., 1986, Costly monitoring, financial intermediation, and equilibrium credit rationing, Journal of Monetary Economics 18: 159-79 